\title{
Urbanization and Daughter-Biased Parental Investment in Fiji
}

\author{
Dawn B. Neill
}

\begin{abstract}
Parental investment decisions guide parental actions regarding children's productive work and are shaped by ecological context. Urban ecology enhances long-term payoffs to investment in human capital, increasing opportunity costs for work performed by children, and decreased workload should result. Using an embodied capital framework, self-reported data on urban and rural Indo-Fijian children's work activities are compared. Results show higher workloads for older children, rural children, and girls. High scholastic achievement is associated with lower workloads for girls, but not boys. This pattern is interpreted as daughter-biased investment in the context of urbanization.
\end{abstract}

Sex-specific parental investment can be viewed as a parental strategy for optimizing reproductive returns on parental investments, given ecological conditions (Clarke and Low 2001). However, unraveling the specific factors that impact biases in parental investment may be complicated. Sex-specific investment biases may be part of parental strategies to improve future fitness returns from offspring likely to have better future reproductive success, given parental condition, or responses to specific local factors that enhance or limit access to resources or mates. The Trivers-Willard model proposes that, in situations where reproductive variance is higher among males and offspring are sensitive to parental resources, parents in good condition should bias investment toward sons since high-quality sons will typically have relatively higher reproductive returns, and parents of poor condition should bias investment toward daughters rather than raise lower-quality sons that will suffer relatively lower reproductive returns (Trivers and Willard 1973). Local resource 
competition models explore the effect that future competition over resources or mates has on parental investment biases, with the expectation that investments are biased in favor of the noncompetitive sex. Alternatively, local resource enhancement models explore how future resource or mate enhancements bias investment in favor of the enhancing sex (Cronk 2007; Sieff 1990).

Many ecological conditions can affect sex biases in investment, including local opportunity structure, family composition (e.g., birth order, number of siblings), the ability of offspring to offset investment costs (e.g., through productive work, alloparenting, old age support, or remittances), dispersal opportunities, and social structure (e.g., patri/matrilocality) (for review see Cronk 2007; Sieff 1990). Strong and persistent son bias has been observed in many Asian countries, including India. Son bias in India has been generally attributed to the strong patrilineal/patrilocal social organization, including support of parents in old age by sons, as well as the limited economic opportunities for women (especially in rural locales) and dowry expense (Das Gupta et al. 2002). Regional analyses indicate that son preference in India is not uniform. Higher-status populations discriminate more strongly against daughters (Murthi et al. 1995), and highly skewed sex ratios are largely associated with high-caste north Indian groups (Edlund 1999). Similarly, variation in sex preference exists among Indian diaspora communities (Purewal 2003). Heterogeneity in son preference among diaspora communities is subject to a host of current ecological, as well as historic and cultural, considerations. Among Jat Sikh families, transnational migrations facilitated through arranged marriage seem to impact parental investment strategies by enhancing the relative value of daughters in the home country. Marriage migrations are shown to facilitate family ties and migration networks that result in additional family members migrating, improve the economic standing of family members remaining in India, and decrease up-front marriage costs by rendering dowry unnecessary (Mooney 2006). Other investigations of migration and sex bias suggest that home-country son biases may be maintained in migrants though the expression of investment biases might change (Gill and Mitra-Kahn 2009). Such inconsistencies indicate that the relative worth of sons and daughters is indeed complex and variable, given individual and ecological particulars. This paper explores sex-biased parental investment among one such diaspora communitycontemporary Indo-Fijians.

Fiji is a small South Pacific island nation. The population of Fiji consists of two main ethnic groups. According to the 2007 population census, Fiji is home to 837,271 people, with indigenous Pacific Islander (ethnic Fijians) comprising about $57 \%$ of the population and Indo-Fijians about 38\% (Fiji Islands Bureau of Statistics 2010). Indo-Fijians are mostly descended from South Asian Indians that came to Fiji as indentured sugarcane laborers under British colonial rule between 1879 and 1916. Research into the Indo-Fijian diaspora indicates that 60,000 laborers were recruited from throughout India. The majority of laborers were of low or scheduled caste status, but some have been identified as coming from higher castes. Despite their initial caste status, the recruitment and indenture process somewhat equalized the status of individuals, eliminating the ascribed status of caste and replacing it with the status of girmitiya (Naidu 2004). In contemporary Fiji, neither the caste system nor formal dowry functions. Following the end of indenture, more than three-quarters of laborers stayed and continued to work as free sugarcane farmers in Fiji. Until 
relatively recently, many Indo-Fijians have remained sugarcane growers. In Fiji more than $90 \%$ of the land is inalienably owned by ethnic Fijian kin groups $(\sim 83 \%)$ or the government, including most farmland, which is managed through a long-term leasing structure (Kelly 1991; Lal 2001). Ongoing land-rights uncertainties and evictions have substantially reduced the number of Indo-Fijians currently engaged in farming (Reddy and Naidu 2001). Since the rural sector offers few other employment options, this has contributed to an above-average rate of rural-tourban migration among Indo-Fijians. In addition to unequal access to land resources, Indo-Fijian people face limits on political expression and power as well as institutionalized discrimination that limits education and employment options. Ethnic Fijian political primacy is enshrined in the constitution, and Indian political progress has generally been met with political coups $(1987,2000,2006)$ that reinforce indigenous rights and political power.

Though variation in wealth, education, and status exists within the Indo-Fijian community, Indo-Fijians as a group face considerable race-based barriers to upward social mobility within Fiji as well as institutionalized resource restrictions. IndoFijians cope with these restrictions in variable ways, facilitated in part through their individual ability to negotiate limited resource access. One well-documented response to unavailable or undependable resources is dispersal (Clarke and Low 1992; Low 1989; Strassmann and Clarke 1998), and the decision to stay or disperse results from both individual factors and ecological constraints (Towner 1999). Human dispersals "may best be understood as a facultative, demographic response to social, ecological, and reproductive options in the local area" (Clarke and Low 2001:643). People migrate in response to ecological constraints but only when dispersal is likely to improve individual access to resources or mates (Low 1989; Towner 1999). Among Indo-Fijians, ecological constraints exist, especially in the form of land resources and opportunities, and dispersal is one means employed to overcome local restrictions. Indo-Fijians have a long history of steady dispersal from Fiji. Between 1970 and 2002, at least 120,000 people have emigrated out of Fiji, with the vast majority being of Indian descent. Emigration is almost exclusively to more developed economies (i.e., Australia, New Zealand, United States, Canada) for employment, education, or marriage (Chandra 2003).

The individual factors that impact successful resource access are ecologically variable and likely to result in large part from parental investment. In urban and urbanizing ecologies, the "threshold level of investment" required for success (Clarke and Low 2001:649) is likely achieved mainly through skill acquisition and formal education (Kaplan et al. 2002). Embodied capital is the lifetime accumulation of the processes of growth, development, and maintenance. Functionally, "embodied capital includes strength, immune function, coordination, skill, and knowledge" (Kaplan et al. 2002:236). The theory of embodied capital relies on the assumption that humans possess an evolved psychological mechanism that is sensitive to prevailing ecological conditions and in response allows parents to make adjustments in allocations of limited resources. The fact that wage labor is inherently tied to learned skill sets creates an incentive for increased investments in learning for skillsbased resource acquisition and increases the opportunity costs for children who spend time in other activities. In wage-based, urban economies, offspring quality is primarily improved through formal education, which is largely incompatible with 
child productive tasks. Urban ecology increases the opportunity costs for children to engage in productive work, and lower levels of work are predicted to result. Though children's work may have an immediate return for a household, parents are expected to trade some level of short-term returns from such work for educational investment that will result in higher long-term returns from experience-based embodied capital (Bock 2002).

Here, I examine the trade-off between children's productive work and educational investment among Indo-Fijian families. Cross-culturally, girls tend to contribute more to household productivity than boys (Whiting and Edwards 1988), and it is expected that Indo-Fijian girls will contribute more through productive work than boys. The persistence of a patrilineal/patrilocal social structure among Indo-Fijians and the dearth of economic opportunities for females throughout rural areas of Fiji should favor parental investment in sons-at least in rural areas. Urban-living parents should recognize and respond to the increased economic opportunities available to skilled workers, including females. Research has shown that education is positively associated with urban living (Pekkala 2003) and that human capital generates higher returns in urban than rural areas (Huang et al. 2002); these returns are recognized through greater work opportunities for the college-educated (Costa and Kahn 2000). An embodied capital approach (Kaplan 1996; Kaplan et al. 2002) suggests that urban environments yield higher payoffs to educational attainment and that parents might favor a trade-off between productive work and time spent studying. Though the urban ecology provides potentially higher payoffs to educational investment in sons and daughters, the relative difference in economic opportunities is greater for girls. In keeping with an embodied capital approach, I predict that urban girls, on average, will contribute relatively less than rural girls and that parents will show a daughter bias resulting in decreased productive work for some girls - specifically, girls who perform well in school. Earning high grades should be an indication of the capacity for continued success in school and high educational attainment. Thus, high-performing girls might be good candidates for dispersal (through either hypergynous marriage or skills-based labor migration) and the trade-off between productive work and time spent studying will favor even lower levels of productive work. The motivation for investment biases will be evaluated through qualitative data. If parents are indeed making investment decisions in order to access hypergynous marriage or skill-related job opportunities for girls, parents should favor future emigration, especially for daughters.

\section{Methods}

Sample

Data presented here were collected from 2004 to 2005 among Indo-Fijian families in two areas of Fiji. Data collection was designed to yield three sample groups: highincome urban, low-income urban, and rural. The urban study population is drawn from Suva City, the capital of Fiji and by far the most urban area in the country. The rural population is drawn from the sugarcane farming community near Rakiraki town on the north part of the main island of Viti Levu. Data collection relied on 
random cluster sampling, with high-income urban areas over-sampled to ensure adequate numbers of high-income households in the final sample. Urban clusters were identified based on national census designations. Since such designations did not exist for rural areas at the time of data collection, geographic clusters of households were identified and randomly chosen for sampling. A large segment of the urban data ( 85 households) came from squatter settlements (Jittu Estates and Nanuku) in Suva.

Within each cluster, $100 \%$ of Indo-Fijian households with children between 5 and 16 years of age were targeted. Data were collected with approval from the University of Washington's Institutional Review Board (Application No. 03-0236-C02) as well as the Fiji Ministry of Education. Data collection took one to two hours per household and consisted of a quantitative survey, qualitative interview, and standard anthropometric measuring of mothers and children. Data were collected from 232 urban households, a response rate of $89 \%$, and 116 rural households, a response rate of $98 \%$. Twelve urban and two rural households were deemed unusable because they do not contain biological mother-child pairs, leaving 334 households in the data set. For the analyses presented here, only children six and one-half years of age and older are included since they will have completed at least 1 year of school. An additional 13 children have not been included in analysis because no one in their household could provide accurate educational performance data or school report cards. The data analyzed here represent 502 children aged 6.5 to 16 years; 192 rural children from 107 households and 310 urban children from 199 households.

\section{Measurement}

Child Productive Work Estimates of productive work were ascertained through selfreported data collected by survey questionnaire. Children were questioned in the presence of their mother, with mothers validating the responses of older children and generally answering for younger children. Work activities included in the questionnaire were determined to be appropriate through prior interviews and discussions with cultural consultants. Once developed, the activities list was administered as part of the larger survey. The activities list consists of 18 productive tasks commonly done in urban and/or rural areas. To gauge the impact of environment on productive work, the same list of activities was given in both urban and rural areas. Level of participation in each activity was recorded based on frequency of participation (Table 1, "Original"). Frequency values were then converted to a monthly work count (Table 1, "Converted"). This summary value was non-normally distributed with over-dispersion and skewed to the right owing to a generally low frequency of work (Fig. 1). The summary value was square root transformed to normalize its distribution and analyzed with a Gaussian distribution. Validity of the productive work self-report data was ascertained by subjective comparison of these data to focal follow observational data collected on 80 study participants. Over the course of data collection, focal follow participants each spent one full day being observed by a local researcher, who recorded all the activities in which the participant engaged throughout the day. Because the focal follows record activity for one day and the questionnaire seeks to estimate work productivity over a full month, an exact validity score could not be calculated. Rather, focal follow logs 
Table 1 Activities list and scale. Self-reported engagement in all activities by rural and urban children was recorded during household interviews. Data were recorded on the "Original" scale and then converted to a monthly frequency ("Converted") to establish a relative measure of individual work engagement for use in analysis

\begin{tabular}{lllc}
\hline & & \multicolumn{2}{l}{ Scale } \\
\cline { 3 - 4 } List of activities & & Original & Converted \\
\hline Cook & Care for siblings & Never & 0 \\
Prepare food & Garden & 1 every $2-$ & 0.5 \\
Shop & Cut/load cane & 1 months & 1 \\
Clean (own room, etc.) & Load/carry other crops & $1 /$ week & 4 \\
Sweep & Carry fuel wood & $2-5 /$ week & 12 \\
Wash clothes & Carry water & $\geq 1 /$ day & 30 \\
Wash car/truck & Tend cattle/animals & & \\
Wash dishes & Fish & & \\
\hline
\end{tabular}

were examined to assess whether activities that were reported as being done daily or almost every day were generally observed during the focal follow and activities reported as never or almost never being done were rarely observed. Focal follow logs showed a strong similarity to self-report questionnaire data.

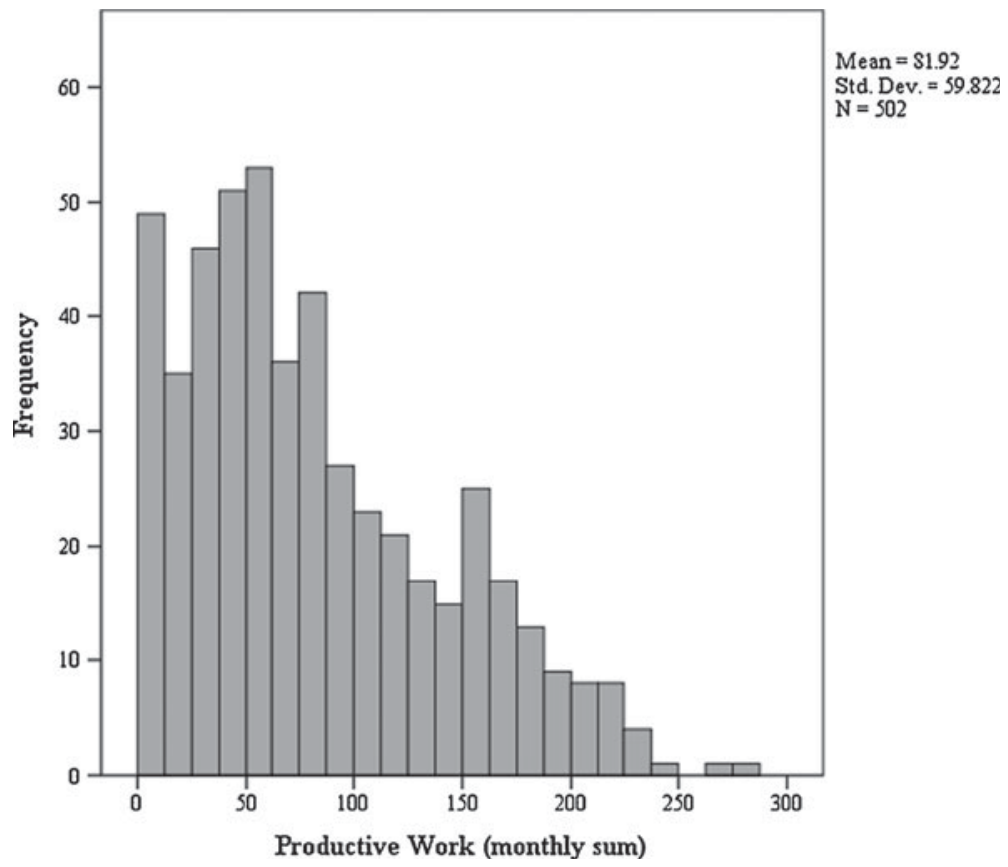

Fig. 1 Work frequency distribution: The original distribution of productive work shows combined, selfreported, monthly productive work level. The non-normal distribution was square-root transformed for analysis (not shown) 
Educational Performance Several questions regarding educational performance were included in the survey questionnaire. To assess educational performance, averages of the highest and lowest grades (converted to a 100-point scale) earned by each child were used. Children were found to be mainly on track in age-for-gradelevel enrollment. However, considerable variation is apparent when educational performance is assessed by grades earned. Therefore, grades earned, rather than grade-level enrollment, was chosen as an indicator of educational performance. Grades come mainly from self-report by parents of each student. Throughout the study, parents were randomly asked to verify grades by showing a recent report card. Report cards confirmed that parents accurately reported children's grades. Parents and students reported the highest $($ range $=11-100$, median $=89$, mean $=84$, s.d. $=15$ ) and lowest (range $=0-100$, median $=56$, mean $=57$, s.d. $=20$ ) grades earned in school for each child. These were converted to percentages. For purposes of this analysis, an averaged value of self-reported high and low school grades is used (Table 2).

Analyses Linear regression (STATA 11) is employed to assess sex-specific productivity and the effect of school performance on level of productive work. The summary value for productive work is the dependent variable. Robust standard error estimation is used to account for the lack of independence between children living in the same households. The regression is adjusted for age (years) and sex $(0=$ female, 1=male). Group differences by sex and environment were assessed using ANOVA (SPSS 19). Least Significant Differences (LSD) post-hoc tests are used to assess significance of between-group differences. Qualitative data were analyzed and coded for relevant themes. Qualitative data come from short, semi-structured

Table 2 Descriptive statistics by ecology, with average monthly productive work and average grades shown by ecology and sex. Mean productive work is significantly different between all groups. Mean average grade varies significantly between urban girls and all other groups and between urban and rural boys. No significant differences exist between rural girls and urban boys

\begin{tabular}{|c|c|c|c|c|}
\hline & \multicolumn{2}{|l|}{ Urban $(N=310)$} & \multicolumn{2}{|l|}{ Rural $(N=192)$} \\
\hline Percent female & \multicolumn{2}{|l|}{54.5} & \multicolumn{2}{|l|}{52.6} \\
\hline Age (range, s.d.) & \multicolumn{2}{|c|}{$10.9^{\mathrm{a}}(6.5-16.7$, s.d. $=2.6)$} & \multicolumn{2}{|c|}{$11.9(6.6-16.8$, s.d. $=2.8)$} \\
\hline $\begin{array}{l}\text { Number of children } \\
\text { in household }\end{array}$ & \multicolumn{2}{|c|}{$2.7^{\mathrm{a}}(1-6$, s.d. $=1.0)$} & \multicolumn{2}{|c|}{$3.3(1-7$, s.d. $=1.3)$} \\
\hline Income (F\$) & \multicolumn{2}{|c|}{$\begin{array}{l}24,619^{\mathrm{a}}(1,820-186,000 \\
\text { s.d. }=30,318)\end{array}$} & \multicolumn{2}{|c|}{$7,934(600-52,000$, s.d. $=6,161)$} \\
\hline Highest grade & \multicolumn{2}{|c|}{$86^{\mathrm{a}}(37-100$, s.d. $=14)$} & \multicolumn{2}{|c|}{$81(11-100$, s.d. $=16)$} \\
\hline Lowest grade & \multicolumn{2}{|c|}{$60^{\mathrm{a}}(0-100$, s.d. $=20)$} & \multicolumn{2}{|c|}{$54(2-98$, s.d. $=18)$} \\
\hline \multirow[t]{2}{*}{ Average grade } & \multicolumn{2}{|c|}{$73^{\mathrm{a}}(29-100$, s.d. $=15)$} & \multicolumn{2}{|c|}{$68(7-99$, s.d. $=15)$} \\
\hline & Male $(N=141)$ & Female $(N=169)$ & Male $(N=91)$ & Female $(N=101)$ \\
\hline Average grade & $71^{\mathrm{c}}$ & $75^{\mathrm{b}}$ & 66 & 69 \\
\hline Productive work & $5.9^{\mathrm{a}}$ & $8.0^{\mathrm{a}}$ & $9.1^{\mathrm{a}}$ & $11.4^{\mathrm{a}}$ \\
\hline
\end{tabular}

adiffers from other group(s) at $p \leq 0.01,{ }^{\mathrm{b}}$ differs from other groups at $p \leq 0.05,{ }^{\mathrm{c}}$ differs from rural boys at $p \leq 0.05$ 
interviews with mothers following administration of the quantitative questionnaire. The interview questions sought to explore domains related to offspring education, occupational aspirations, migrations, and gender biases. Questions were open-ended. In order to gauge occupational aspiration, respondents were asked to discuss the employment of household residents and extended family and then were asked if those jobs would be suitable for each offspring. The interview also sought to establish whether the family had migrated within Fiji. As part of understanding internal migration aspirations, we asked where parents thought their children would live and work once they finished schooling. We did not ask about relatives living abroad or family who had emigrated. Emigrant kin networks and emigrant aspirations, however, emerged as prominent issues impacting parental investment.

\section{Results}

Descriptive statistics are shown in Table 2. As expected, results confirm that girls do more productive work than boys and that rural girls do more work than urban girls (Figs. 2 and 3). Regression results show that being male significantly reduces productive work, as does residing in the urban environment (Table 3). Initially, income $(p>0.75)$ and quantity of children $(p>0.10)$ were included in the model. Because neither was significant, they were removed from the final model (Table 3).

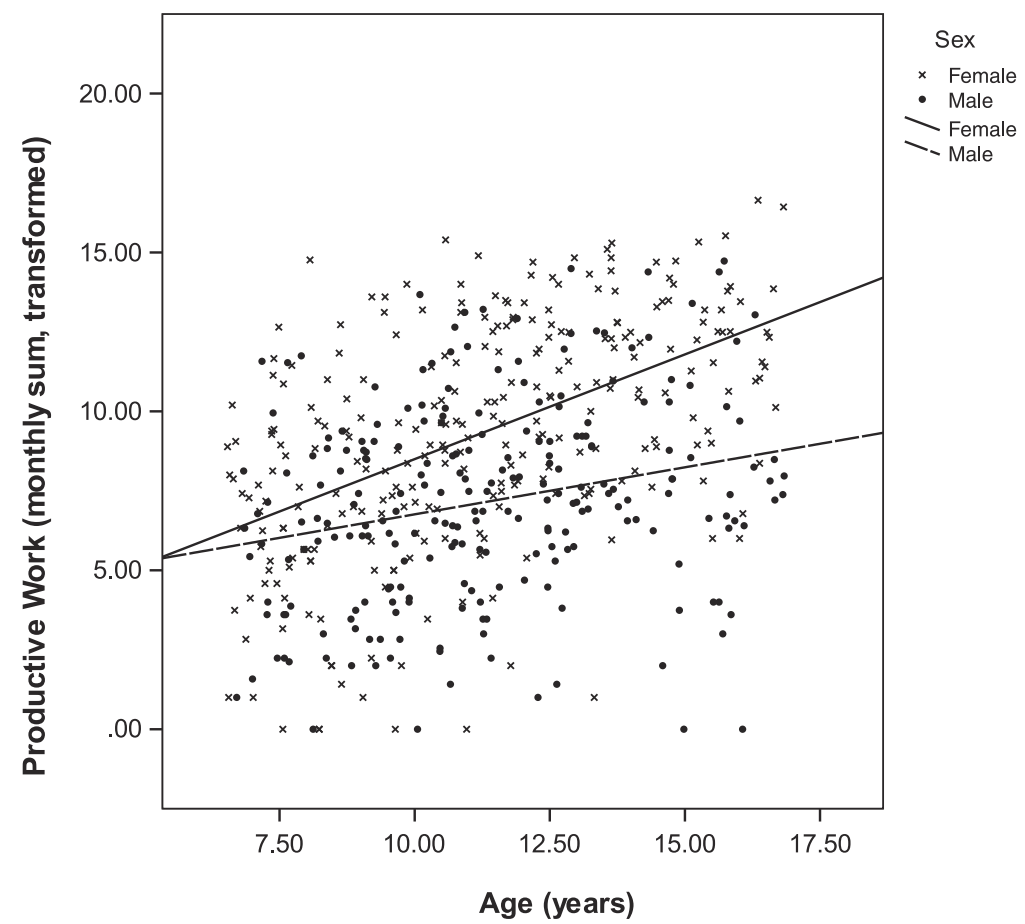

Fig. 2 Association of productive work to age and sex: The monthly sum of productive work increases for both boys (dashed) and girls (solid), with productive work by girls increasing more steeply with age 
Fig. 3 Productive work by sex and environment. The average monthly sum of productive work is highest among rural girls (mean=11.4), followed by rural boys (mean $=9.1)$, urban girls $($ mean $=8.0)$, and then urban boys $($ mean $=5.9)$. Mean productive work level varies significantly between all groups (ANOVA $\mathrm{F}=66.7$, $p \leq 0.01)$

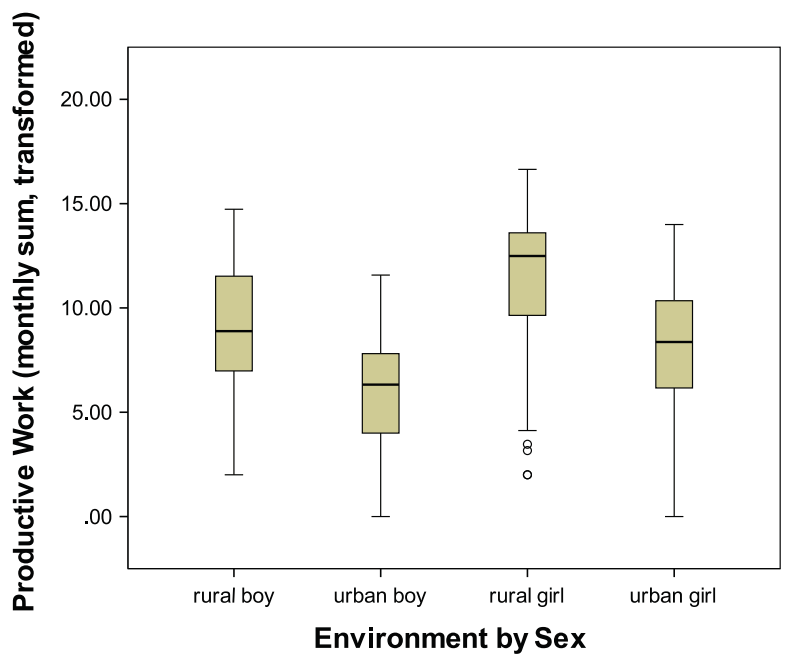

Results also confirm that rural girls do significantly more work than any other group (Table 1, Fig. 3). Scholastic achievement is negatively associated with productive work (Table 3), and productive work decreases as grades improve, but only for girls (Fig. 4).

Qualitative data provide rich context for interpreting some aspects of parental investment among Indo-Fijians. Three main themes relevant to parental investment goals emerged. The first theme captures the importance of education as a means to a "good job." As might be expected in many urban and urbanizing economies, parents see education as the key to a happy and secure future for their children. About onequarter of respondents make overt claims pinpointing educational attainment as the means to future happiness: "We tell our children the more educated you are, the brighter your future will be" (Mother, Rakiraki); "I just want her to study hard and get a good job so that her future is bright" (Mother, Suva). Often, these statements suggest that the independence that comes from education is of primary importance for daughters: "I want [her] to be educated. ... When she gets educated and stands on her own feet it'll be good" (Mother, Suva). Other mothers go further, suggesting that

Table 3 The effect of educational performance, age, sex, and area on productive work. Age $(p \leq 0.00)$ and sex $(p \leq 0.00)$ are significant predictors of productive work, with girls doing significantly more work and work, increasing with age. Urban ecology significantly reduces the amount of productive work $(p \leq 0.00)$. Earning high grades is a significant predictor of productive work but only for girls $(p \leq 0.04)$. Annual income $(p \leq 0.91)$ and total number of children $(p \leq 0.11)$ were not significant and were removed from the model $\left(\mathrm{R}^{2}=0.39\right)$

\begin{tabular}{lccccl}
\hline DV=Work & Coefficient & Robust SE & \multicolumn{1}{l}{$t$} & $p$ & $95 \%$ CI \\
\hline Age $($ yrs $)$ & 0.413 & 0.053 & 7.74 & 0.00 & {$[0.308,0.518]$} \\
Sex $(0=$ female, $1=$ male $)$ & -4.785 & 1.277 & -3.75 & 0.00 & {$[-7.298,-2.273]$} \\
Urban area $(0=$ rural, 1= urban $)$ & -2.829 & 0.308 & -9.19 & 0.00 & {$[-3.435,-2.224]$} \\
Average grade & -0.021 & 0.014 & -1.54 & 0.13 & {$[-0.048,0.006]$} \\
Grade * Sex & 0.036 & 0.017 & 2.05 & 0.04 & {$[0.001,0.070]$} \\
Constant & 7.957 & 1.305 & 6.10 & 0.00 & {$[5.388,10.526]$} \\
\hline
\end{tabular}




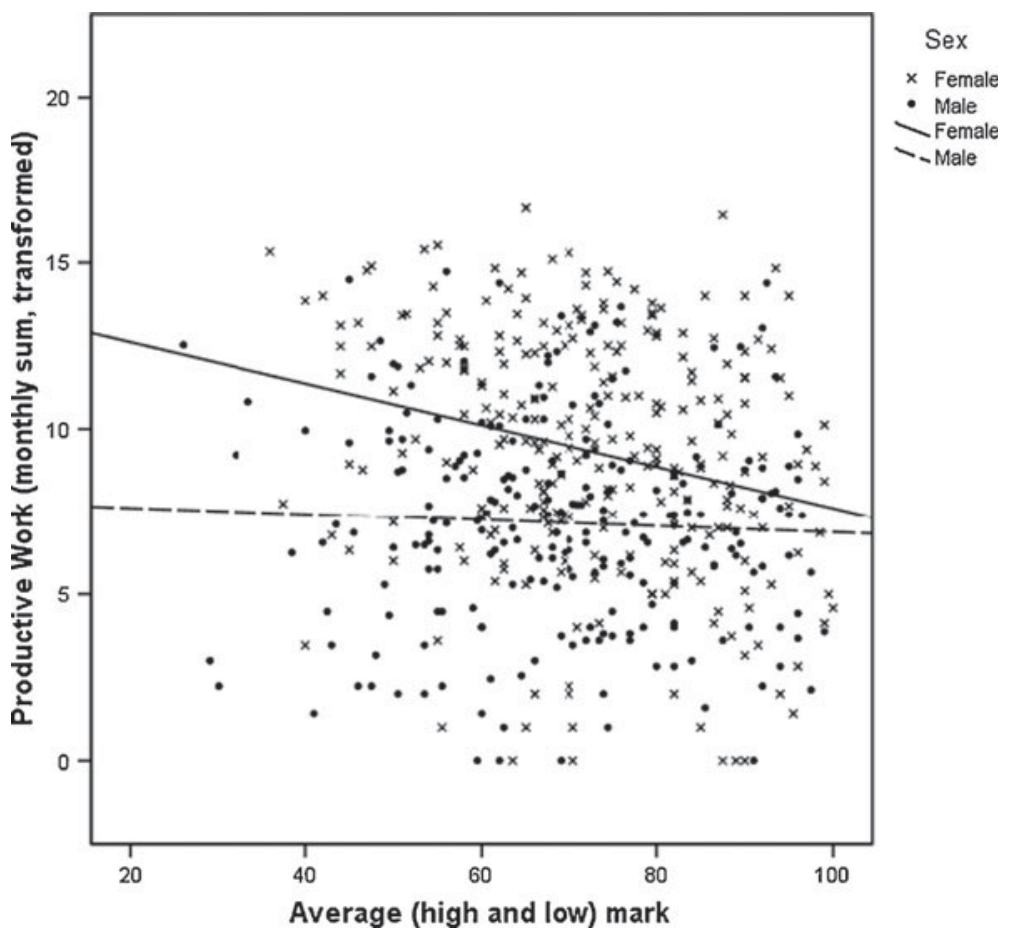

Fig. 4 The interaction of sex and educational performance on productive work. The monthly sum of productive work decreases as average grades earned increases, but only among daughters (solid)

education and a professional job are the only means to independence for daughters: "Only then [with a good job] will she be able to make a good wage and stand on her own feet" (Mother, Suva); "It's better to be on your two feet rather than depending on the husband. . . . you don't know how things [might] change. If you have a qualification, then you can do anything if your husband goes away" (Mother, Suva). The desire for highly educated, professionally employed children is by no means universal. Parents seem to be both realistic and strategic in the construction of aspirations. Parents clearly vary their expectations based on offspring ability: "He is not a very bright student. I give him advice all the time. Since he is not very smart, a mechanic or a driver's job would do for him" (Mother, Suva).

The second theme emerging from the qualitative data is the socioecological context of female-appropriate work among Indo-Fijians. The vast majority of parents state high expectations for daughters (nearly 70\%). Generally, they expect that one or all of their daughters will perform well in school, go on to receive a diploma or degree in a professional field, and work in a professional occupation. For sons, however, expectations are much more variable, with about one-quarter of parents aspiring for their sons to hold trades jobs instead of professional jobs in the future. Parents do hope that some sons will earn degrees or diplomas and become doctors, lawyers, or accountants. But many parents also see trades jobs as a good alternative to professional careers for sons: "A technician profession is good, it has trade [is in demand]" (Mother, Suva); "[He should hold a] good job like a mechanical job" (Mother, Rakiraki); "I think he would be a very good 
trades person: blue-collar job, mechanical or panel beating or even carpentering" (Mother, Suva). Alternatively, most parents state strongly that they hope to avoid having daughters engaged in trades jobs, or any occupation deemed risky, lowskill, or reputationally damaging: "[I don't want her to do] jobs like house girl or in the garment factory. If you do those, you don't have any other options and those jobs are not good for your name [reputation]" (Mother, Suva). With the exception of farming, parents didn't consistently name any occupations as generally substandard for male employment: "I want my daughter to get educated and get a good job such as an accountant, and for my sons, any good job" (Mother, Suva). Though some parents listed jobs, such as taxi driving, as risky and undesirable for males, these same jobs were listed as prohibited for females because they don't offer good wages or job security, and they seem to carry a stigma that runs contrary to ideals of female purity. For parents with both daughters and sons, semi-structured interviews often revealed obvious biases in aspirations for sons and daughters:

Interviewer: What jobs do you want your daughter and son to do in the future?

Mother: I want [my son] to be a motor vehicle mechanic and for [my

daughter], a teacher or accountant. ... I would actually accept [him] doing a

sales job, but not [her] because she's a girl.

Interviewer: How much education do you think they will need?

Mother: [she] should go to USP [university] and [him], he can manage until

form 7.

Overt daughter biases were stated by $30 \%$ of households with daughters present. Daughter-biased statements frequently pointed both to the importance of education and professional work for girls and to trades as an acceptable alternative for boys: "[my son] will finish form 6 [12th grade] and be a mechanic, but [my daughter] will go on to USP for accounting. . . . it is so important for girls to get a good education and be able to stand on their own feet" (Mother, Suva).

The third theme regarding parental investment is the importance of emigration as part of the long-term payoffs to investment decisions. Most Indo-Fijian parents suggest that urban migration or more extreme emigration out of Fiji is an important component of their long-term strategy. More than $60 \%$ of parents are pro-emigration, with the vast majority making statements favoring emigration as favorable to offspring success, especially given the resource constraints within Fiji: "If they go to overseas - much better. We don't have many facilities, land is always a problem here. . . competition is tight so that profit is very low. . . we are trying our best that they go to overseas" (Mother, Suva). For daughters, this comes from both marriage and employment opportunities abroad: "My daughter will be educated and able to find a good husband abroad" (Mother, Suva); "If [my daughter is an] accountant she can go overseas" (Mother, Suva); "I want [my son and daughter] to do something that would be easy for them to migrate" (Mother, Suva). Parents also hope for sons to migrate, but generally for work, not for marriage. Parents often state that one reason they want their sons doing trades jobs is as a pathway for emigration: "[he should get] a good job, like a mechanical job - a trades job, which is good for going to overseas" (Mother, Rakiraki). 


\section{Discussion}

Research on child productive work has shown that children engage in both economic and domestic work at levels that vary across cultures and ecologies and that level of productivity is shaped by task availability and the associated costs, benefits, and opportunity costs (Kramer 2005). Urban ecology modifies the trade-offs to long-term investments in human capital, thereby increasing the opportunity costs for children to participate in productive activities, and lower levels of work should result. The results reported here indicate that productive work varies by individual (i.e., age, sex, and educational performance) and ecological factors (urban vs. rural environment). As expected, girls do more work than boys overall, and rural girls do the most work (Figs. 2 and 3). It is possible that child productivity in Fiji is simply conditioned by task availability, with urban children being less productive primarily because there are fewer age-appropriate productive tasks for them to perform. However, an embodied capital approach would suggest that the opportunity costs to engaging urban children in productive work are higher, especially for certain children, and that decreased work levels should result. These results support an embodied capital approach. The array of productive work tasks available to urban and rural children varies, primarily because urban households have fewer animals and gardens to tend. Nonetheless, urban parents could compensate by engaging children in higher levels of other productive tasks. Given that urban mothers tend to have few helpers, forgoing engagement of children in productive work would seem to increase the cost of childrearing.

Girls do more work than boys. Despite this, it is only among girls that scholastic achievement affects levels of productive work (Table 3, Fig. 4). Not only do parents seem to demand less productive work from daughters who perform well in school, parents express higher aspirations for daughters overall relative to sons. It is possible that instead of good grades decreasing productive work demands, children who already have reduced household work demands may be able to concentrate more on their studies and earn higher grades. If this were the case, one might predict that boys, who already engage in significantly lower productive work than girls, would earn better grades. In urban and rural areas, however, boys earn lower grades, on average, than girls (Table 2). Though demonstrating causality is impossible, taken together, these results indicate an embodied-capital-type trade-off favoring daughters among Indo-Fijians.

Many ecological and individual factors can affect sex biases in parental investment, and in some cases, parents may be responding to multiple ecological cues. Frequently, daughter-biased investment occurs when social contexts allow daughters to marry up, sometimes by marrying out. Daughters who succeed in marrying into higher-status families accrue immediate fitness benefits from increased resources channeled into fertility or investment. They may gain additional long-term fitness benefits by virtue of producing offspring who benefit from their higher status. These benefits may be realized through enhanced mating opportunities (e.g., polygyny of sons), enhanced inheritance, or escape from prevailing discriminatory practices (e.g., those associated with strictures on caste). Daughter-biased investment has been shown among several low-resource or low-status populations, including the Mukogodo (Cronk 1989), the Ifaluk (Turke 1989), low-income Americans (Gaulin 
and Robbins 1991), and in historical records of peasants in Germany (Voland and Dunbar 1995) and Portugal (Boone 1986). Daughter-biased investment has also been documented along a socioeconomic gradient in the Arisi Oromo, a patrilineal population in rural Ethiopia (Gibson 2008). Widowed mothers who remain unmarried are highly economically constrained, relative to married mothers. Though a strong son preference exists within the Arisi Oromo, clear daughter biases in parental investment emerge among widowed women of low socioeconomic status. Tests in contemporary contexts have shown much more variable results as measures of parental investment have expanded to include potentially evolutionarily novel metrics (Cronk 2007), such as educational investment or attainment (e.g., Freese and Powell 1999; Keller et al. 2001). In a study exploring status and educational attainment in the US, high-status sons and low-status daughters were shown to attain significantly higher levels of completed education relative to same-status, oppositesex siblings (Hopcroft 2005). Similarly, among contemporary North American mothers, low-income mothers were shown to nurse daughters significantly longer than sons, and high-income women nurse sons longer than daughters (Gaulin and Robbins 1991). Among the Mukogodo, who are at the bottom of a regional social hierarchy of wealth and status, investment favors daughters. Mukogodo daughters are nursed longer than sons and receive more frequent medical care. Data also show that Mukogodo daughters have higher reproductive success than sons, facilitated through hypergynous marriage with nearby, wealthier groups. These studies fit the predictions of a Trivers-Willard model.

Though Indo-Fijians are situated at the bottom of a national status hierarchy, relative to ethnic Fijians, difficulties arise in interpreting these results as a TriversWillard effect. Indo-Fijian parents do not seek to raise daughters who might marry into the higher-status (indigenous) population. Interethnic marriage rates within Fiji have been and remain low. Marriages to men of Indian or European descent residing outside of Fiji could be considered hypergynous and certainly do occur, though official statistics documenting the frequency of these marriages are lacking (Chandra 2003). Parents' interview statements suggest that finding a high-status husband outside of Fiji is one route that emigrant daughters take to improve status and resources. Other studies have suggested that marriage to an overseas-born spouse is an important emigration route for Fijian women (Chandra 2003:8). Indo-Fijian females consistently emigrate in higher numbers than males, and the female bias is most skewed for women of marriageable age, 15-24 years old (Chandra 2003). Other studies exploring the context of transnational marriages point to the importance of education in arranged marriages (Lateef 1993, Sherani 2009). Female education is a desired trait, especially by grooms' parents in the context of arranged marriage. An "ideal bride" is described as physically attractive, educated, and having a good reputation (Sherani 2009:98). In addition, potential grooms describe wanting a wife who can contribute financially to the household (Sherani 2009). Though no data specifically address the relative status, wealth, or fertility gains that women achieve through transnational marriage, qualitative statements strongly suggest that parents perceive that greater long-term benefits for their daughters and future grandchildren can be gained through emigration and marriage. Marrying a man with permanent residence status overseas offers "an opportunity of a better economic and social life abroad" (Sherani 2009:95). Better economic prospects arise from relative 
income gains. For example, a registered nurse in Fiji earns a starting salary of about F $\$ 11,000$ (US\$6,000), whereas a registered nurse in Australia can expect to earn a starting salary of around AU $\$ 40,000$ (US\$40,000). Social benefits include potential land ownership, reduced discrimination, and increased personal safety (Chandra 2003).

Daughter-biased investment has also been demonstrated in response to local factors. A local-resource-enhancement model has been supported in a number of human populations. Hutterites (Margulis et al. 1993), Hungarian Gypsies (Bereczkei and Dunbar 1997), and women of Bwa Mawego in Dominica (Quinlan et al. 2005) have all been shown to nurse daughters longer than sons because daughters provide substantial household help, enhancing household resources and parental fitness. For Gypsies, parental investment motives may, however, be more complex. Hungarian Gypsies are situated at the bottom of a social hierarchy that also includes ethnic Magyar Hungarians. A Trivers-Willard model would suggest that Gypsy mothersthose of lower socioeconomic status in the larger social hierarchy-might invest more in daughters as a way of increasing future fitness gains. Gypsy females not only are breast-fed longer but also are sent to school longer and are more likely to engage in hypergynous marriage than their brothers, supporting both local resource enhancement and Trivers-Willard effects. An investment bias response to local resource competition has been demonstrated among historic Irish and German farming populations. Among Irish farmers, dispersals took place in response to ecological constraints on land resources and poor alternative economic and reproductive prospects for sons of landed farmers (Strassmann and Clarke 1998). Similarly, in the German Krummhörn population, competition among brothers likely stimulated emigration among unmarried males with high numbers of same-sex siblings (Voland and Dunbar 1995). In both instances, land resources were demonstrated as being important to the reproductive prospects of dispersing males.

Among Indo-Fijians, ecological constraints exist, especially in the form of land resources and opportunities. Parental investment patterns may be a response to local factors. Indo-Fijian parents express concern for their children's futures and suggest that formal education is a path to occupational success, independence, security, and long-term happiness, whether within Fiji or abroad. Between 1982 and 2005, female labor force participation in Fiji increased $150 \%$, while male participation increased only $35 \%$ (Narsey 2007). As the labor market opens up to females, parents may respond by shifting educational investment toward daughters. In Fiji, Indo-Fijian women can access a variety of white collar jobs, such as accounting, nursing, and teaching, which provide stable, steady long-term employment and financial security. There are, however, few options for unskilled Indo-Fijian women, with most unskilled women finding employment as domestic servants, counter clerks, or garment factory workers. These jobs are poorly paid, offer little long-term security, and may be considered reputationally damaging. Underperforming males, however, can pursue a variety of blue-collar (trades) jobs, many of which provide stable and respectable, long-term job opportunities both in Fiji and abroad. In addition, as noted above, the relative income gains for skilled workers who emigrate are substantial.

Interpreting these results in terms of local factors highlights the potential motivational complexities leading parents to bias investments (e.g., Quinlan et al. 2005). Parents are not biasing educational investment toward daughters to enhance 
local resources in typical ways. They do not seem to anticipate helper daughters remaining close to home (e.g., helpers at the nest) to facilitate the parents' future reproductive success. Nor are parents biasing investment toward daughters solely to reduce future competition over local resources. Shifting educational investments toward daughters effectively functions to increase competition between sons and daughters for available professional positions. Instead, parents seem to be altering investments for sons and daughters in ways that decrease competition and enhance resources. Though substantial individual variation exists, parents employ a combined strategy that concentrates educational investments in daughters, channels some sons into less-competitive trades jobs, and encourages offspring emigration. Emigration is predicated on skills. For sons, skilled migration is a function of either technical training or professional employment. For daughters, emigration is a function of either marriage or professional employment (Chandra 2003). Unlike employment in trades for sons, emigration-related hypergyny still requires relatively high educational attainment to ensure daughters are of high enough quality to marry up. As has been demonstrated elsewhere in the Indian diaspora, transnational migrations can enhance resources in the home country through establishing or enhancing migration network ties and remittances (Mooney 2006).

Indo-Fijians continue to flow from Fiji. Estimates are that by 2030, Indo-Fijians will make up only about $25 \%$ of the projected million inhabitants of Fiji. Parents, siblings, and more distant kin rely on skilled emigrants to help facilitate additional migrations. Data presented here suggest that high scholastic achievement among girls is associated with lower levels of productive work. This is interpreted as a parental investment response to urbanization and ecological constraint. Qualitative data reveal three main themes regarding daughter-biased investment in education: education as the means to a good job, socioecological context of female-appropriate work, and the importance of emigration to long-term investment payoffs. Each theme suggests that educational investment bias may be the result of social and economic changes associated with urbanization. By investing in high-performing daughters, parents seem to be responding to the potential long-term payoffs for educated daughters through hypergynous marriage or occupational emigration.

Acknowledgments This research has been supported by National Science Foundation. Dissertation Improvement Grant, BCS-0413900; the Center for Studies in Demography and Ecology and the Department of Anthropology, University of Washington. I wish to thank the Indo-Fijian study participants, without whom this research would not exist. I would also like to thank the reviewers and editors of Human Nature for their helpful comments on the paper, and particularly my advisor, Donna Leonetti.

\section{References}

Bereczkei, T., \& Dunbar, R. I. M. (1997). Female-biased reproductive strategies in a Hungarian Gypsy population. Proceedings of the Royal Society London, 264, 17-22.

Bock, J. (2002). Learning, life history, and productivity: children's lives in the Okavango Delta, Botswana. Human Nature, 13, 161-197.

Boone, J. (1986). Parental investment and elite family structure in preindustrial states: a case study of late medieval-early modern Portuguese genealogies. American Anthropologist, 88, 859-878.

Chandra, D. (2003). Fiji's international migration in the context of human development: gender trends, motivations and strategies. Paper presented at the Economic and Social Commission for Asia and the 
Pacific's Ad hoc Expert Group Meeting on Migration and Development. Accessed at: http://www. unescap.org/esid/psis/meetings/migrationaug2003/Report.pdf

Clarke, A. L., \& Low, B. S. (1992). Ecological correlates of human dispersal in 19th century Sweden. Animal Behaviour, 44, 677-693.

Clarke, A. L., \& Low, B. S. (2001). Testing evolutionary hypotheses with demographic data. Population and Development Review, 27, 633-660.

Costa, D. L., \& Kahn, M. E. (2000). Power couples: changes in the locational choice of the college educated, 1940-1990. Quarterly Journal of Economics, 115, 1287-1315.

Cronk, L. (1989). Low socioeconomic status and female-biased parental investment: the Mukogodo example. American Anthropologist, 91, 414-429.

Cronk, L. (2007). Boy or girl: gender preference from a Darwinian point of view. Ethics, Bioscience and Life, 2, 23-32.

Das Gupta, M., Zhenghua, J., Bohua, L., Zhenming, X., Chung, W., \& Hwa-Ok, B. (2002). Why is son preference so persistent in East and South Asia? A cross-country study of China, India and the Republic of Korea. Policy Research Working Paper Series 2942. Washington: World Bank. Accessible online at www.worldbank.org.

Edlund, L. (1999). Son preference, sex ratios, and marriage patterns. Journal of Political Economy, 107, $1275-1304$.

Fiji Islands Bureau of Statistics. (2010). Fiji National Census of Population 2007. Suva: Government of Fiji. Accessed at http://www.statsfiji.gov.fj/

Freese, J., \& Powell, B. (1999). Sociobiology, status, and parental investment in sons and daughters: testing the Trivers-Willard hypothesis. American Journal of Sociology, 106, 1704-1743.

Gaulin, S. J. C., \& Robbins, C. J. (1991). Trivers-Willard effect in contemporary North American society. American Journal of Physical Anthropology, 85, 61-69.

Gibson, M. A. (2008). Does investment in the sexes differ when fathers are absent? Human Nature, 19, $263-276$

Gill, A., \& Mitra-Kahn, T. (2009). Explaining daughter devaluation and the issue of missing women in South Asia and the UK. Current Sociology, 57, 684-704.

Hopcroft, R. L. (2005). Parental status and differential investment in sons and daughters: trivers-Willard revisited. Social Forces, 83, 1111-1136.

Huang, T., Orazem, P. F., \& Wohlgemuth, D. (2002). Rural population growth, 1950-1990: the roles of human capital, industry structure, and government policy. American Journal of Agricultural Economics, 84, 615-627.

Kaplan, H. S. (1996). A theory of fertility and parental investment in traditional and modern human societies. Yearbook of Physical Anthropology, 39, 91-135.

Kaplan, H., Lancaster, J. B., Tucker, T. W., \& Anderson, K. G. (2002). Evolutionary approach to belowreplacement fertility. American Journal of Human Biology, 14, 233-256.

Keller, M. C., Nesse, R. M., \& Hofferth, S. (2001). The Trivers-Willard hypothesis of parental investment: no effect in the contemporary United States. Evolution and Human Behavior, 22, 343-360.

Kelly, J. D. (1991). A politics of virtue: Hinduism, sexuality, and countercolonial discourse in Fiji. Chicago: University of Chicago Press.

Kramer, K. L. (2005). Children's help and the pace of reproduction: cooperative breeding in humans. Evolutionary Anthropology, 14, 224-237.

Lal, B. J. (2001). The East Indians of Fiji. In J. M. Fitzpatrick (Ed.), Endangered peoples of Oceania: Struggles to survive and thrive (pp. 33-44). Westport, CT: Greenwood Press.

Lateef, S. (1993). Indo-Fijian marriage in Suva: A little love, a little romance, and a visa. In R. A. Marksbury (Ed.), The business of marriage: Transformations in Oceanic matrimony (pp. 205-230). Pittsburgh: University of Pittsburgh Press.

Low, B. S. (1989). Occupational status and reproductive behavior in nineteenth-century Sweden: Locknevi Parish. Social Biology, 36, 82-101.

Margulis, S. W., Altmann, J., \& Ober, C. (1993). Sex-biased lactational duration in a human population and its reproductive costs. Behavioral Ecology and Sociobiology, 32, 41-45.

Mooney, N. (2006). Aspiration, reunification and gender transformation in Jat Sikh marriages from India to Canada. Global Networks, 6, 389-403.

Murthi, M., Guio, A., \& Dreze, J. (1995). Mortality, fertility, and gender bias in India: a district-level analysis. Population and Development Review, 21, 745-782.

Naidu, V. (2004). Violence of indenture in Fiji. Lautoka: Fiji Institute of Applied Studies.

Narsey, W. (2007). Gender issues in employment, underemployment, and incomes in Fiji. Suva: Vanuavou Publications. 
Pekkala, S. (2003). Migration flows in Finland: Regional differences in migration determinants and migrant types. International Regional Science Review, 26, 466-482.

Purewal, T. (2003). Reproducing South Asian women: Female feticide and the spectacle of culture. In N. Puwar \& P. Raghuram (Eds.), South Asian women in the diaspora (pp. 137-156). New York: Berg.

Quinlan, R. J., Quinlan, M. B., \& Flinn, M. V. (2005). Local resource enhancement and sex-biased breastfeeding in a Caribbean community. Current Anthropology, 46, 471-480.

Reddy, M., \& Naidu, V. (2001). Land tenure system in Fiji: the poverty implications of expiring leases. Development Bulletin, 55, 33-35.

Sherani, Z. (2009). The context of transnational marriage between Indo-Fijian brides from Fiji and IndoFijian grooms in Australia. M.A. thesis, Social Sciences, University of the South Pacific.

Sieff, D. F. (1990). Explaining biased sex ratios in human populations. Current Anthropology, 31, 25-48.

Strassmann, B. I., \& Clarke, A. L. (1998). Ecological constraints on marriage in rural Ireland. Evolution and Human Behavior, 19, 33-55.

Towner, M. (1999). A dynamic model of human dispersal in a land-based economy. Behavioral Ecology and Sociobiology, 46, 82-94.

Trivers, R. L., \& Willard, D. E. (1973). Natural selection of parental ability to vary the sex ratio. Science, $179,90-92$.

Turke, P. (1989). Evolution and the demand for children. Population and Development Review, 15, 61-90.

Voland, E., \& Dunbar, R. I. M. (1995). Resource competition and reproduction: the relationship between economic and parental strategies in the Krummhorn population (1720-1874). Human Nature, 6, 3349.

Whiting, B. B., \& Edwards, C. P. (1988). Children of different worlds: The formation of social behavior. Cambridge: Harvard University Press.

Dawn Neill is an assistant professor of anthropology in the Social Sciences Department at California Polytechnic State University, San Luis Obispo. Her research interests include nutritional anthropology, parental investment, urbanization and the ecology of obesity. She explores these topics through crosscultural and cross-ecological comparisons among rural and urban Indo-Fijian and indigenous Fijian populations in Fiji. 